\title{
AVALIAÇÃO DOS EFEITOS DA TEMPERATURA E VAZÃO DE AR SOBRE A PRODUÇÃO DE PÓ NA SECAGEM DE POLPA DE CUBIU EM LEITO DE JORRO
}

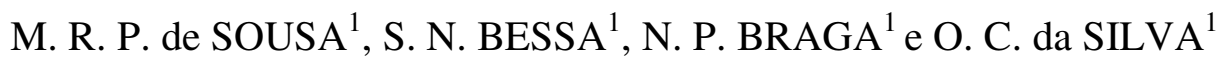 \\ ${ }^{1}$ Universidade Federal do Amazonas, Faculdade de Tecnologia, Departamento de Engenharia \\ Química \\ E-mail para contato: marcos.ruberson@gmail.com
}

\begin{abstract}
RESUMO - O cubiu (Solanum sessiliflorum Dunal) é um fruto nativo da Amazônia, característico por suas boas propriedades nutritivas e aliado da população local no tratamento desde a obesidade ao controle do colesterol. È, todavia, pouco consumido, e uma opção que pode favorecer a sua presença no mercado é o processamento para diminuição de sua perecibilidade, transformando a polpa do fruto em pó, pelo processo de secagem. Neste sentido, o leito de jorro é um equipamento que vem sendo utilizado para tal tipo de aplicação, principalmente por propiciar alto contato entre fases, incrementando a eficiência do processo. Desta forma, o presente trabalho teve como objetivo avaliar a influência da temperatura e da vazão do ar de secagem sobre a produção de pó na secagem da polpa de cubiu em leito de jorro. A partir de um delineamento cúbico composto central, foi feito um conjunto de ensaios cujos resultados permitiram avaliar o efeito das variáveis sobre o rendimento e a taxa média de produção de pó, tendo sido possível concluir que a temperatura foi a única variável influente neste processo.
\end{abstract}

\section{INTRODUÇÃO}

O cubiu (Solanum sessiliflorum Dunal) é um fruto nativo e encontrado em toda a região amazônica, característico por seu sabor ácido e propriedades que lhe conferem uso medicinal. Este atribuído à presença de biocompostos, como fenólicos e carotenoides, que contém ação antioxidante no organismo humano, tendo sido empregado por populações locais no tratamento de mordidas de cobra, picadas de escorpião, infecções cutâneas e ainda como redutor dos níveis de colesterol, glicose e ácido úrico no sangue (SILVA FILHO et. al., 2005).

Destaca-se, além das boas características nutricionais do fruto, a presença considerável em sua constituição da pectina, polissacarídeo de grande auxílio no combate à obesidade, uma vez que diminui a sensação de fome (MERCADANTE et. al., 2013). Apesar deste, entre outros benefícios relacionados ao consumo do fruto, este é relativamente baixo pela população em geral por ser uma fruta exótica e cuja produção é limitada pela baixa demanda, além de ser pouco conhecida em muitas regiões do país. Desta maneira, há espaço para crescimento da sua presença no mercado, o que também faz do processamento uma alternativa viável à sua comercialização.

Neste sentido, o processo de secagem é um dos meios de beneficiamento mais relevantes na indústria de alimentos por ter como resultados a inibição da atividade enzimática e metabólica do 


\section{Congresso Brasileiro de Engenharia Química \\ em Iniciação Científica \\ UFSCar - São Carlos - SP \\ 16 a 19 de Julho de 2017}

fruto e diminuição da proliferação de microrganismos (CÂNOVAS e MERCADO, 1996). Nesta operação, embora ocorra progressiva remoção da umidade e aumento da concentração de componentes presentes na polpa, se dá também a perda de compostos importantes. Isto, portanto, demanda análise para determinação de uma metodologia de secagem que garanta a manutenção das características funcionais e nutricionais do alimento submetido à secagem (FELLOWS, 2006).

Uma alternativa que permite a obtenção de frutos em pó aos métodos mais empregados, que são secagem por spray drying e liofilização, é a secagem em leito de jorro. Este método é caracterizado por possibilitar altas taxas de transferência de calor e massa entre as fases, ocasionando tanto diminuição do tempo como aumento da eficiência do processo (SOUZA, 2009). Apresenta, ainda, grande vantagem sobre os demais processos por ter o custo relativamente menor e permitir a secagem de materiais termicamente sensíveis, a temperatura mais baixa, como é o caso de polpas de frutas tropicais.

Neste contexto, o presente trabalho objetiva avaliar a influência da temperatura e da vazão de ar sobre o rendimento e a taxa média de produção de pó na secagem de polpa de cubiu em leito de jorro.

\section{MATERIAIS E MÉTODOS}

\subsection{Materiais e equipamentos}

Para a realização dos ensaios de secagem, foi utilizada polpa de cubiu obtida por despolpamento manual de frutos in natura, adquiridos em feiras livres. O preparo da polpa envolveu o processo de branqueamento de fatias do fruto despolpado em banho termostático com água, a temperatura constante de $90^{\circ} \mathrm{C}$, durante cinco minutos e arrefecimento com gelo. As fatias passaram então por processador doméstico e em seguida por liquidificador a fim de se obter polpa homogênea.

Quanto ao equipamento de secagem, o leito de jorro, é constituído de estrutura em geometria cilíndrica de base cônica, em aço inoxidável com visor de acrílico. A base cônica tem ângulo de $45^{\circ}$, altura de $8 \mathrm{~cm}$ e diâmetro de entrada de $6 \mathrm{~cm}$. A coluna cilíndrica do leito possui $18 \mathrm{~cm}$ de diâmetro e $90 \mathrm{~cm}$ de altura. Acoplado ao topo da coluna, há um ciclone para separação do pó formado na secagem, do ar.

O equipamento dispõe, também, de um soprador e um trocador de calor elétrico na linha de alimentação do ar de secagem. Uma bomba peristáltica, ligada por mangueira a um ponto na lateral do leito permite a alimentação da polpa. Os equipamentos de medição são: termohigrômetros situados na alimentação e na saída do leito, anemômetro e manômetro diferencial. A disposição do aparato de secagem é ilustrada na Figura 1. 


\section{Congresso Brasileiro de Engenharia Química em Iniciação Científica UFSCar - São Carlos - SP 16 a 19 de Julho de 2017}

Figura 1 - Esquema do equipamento de secagem em leito de jorro (SOUSA Jr., 2012).

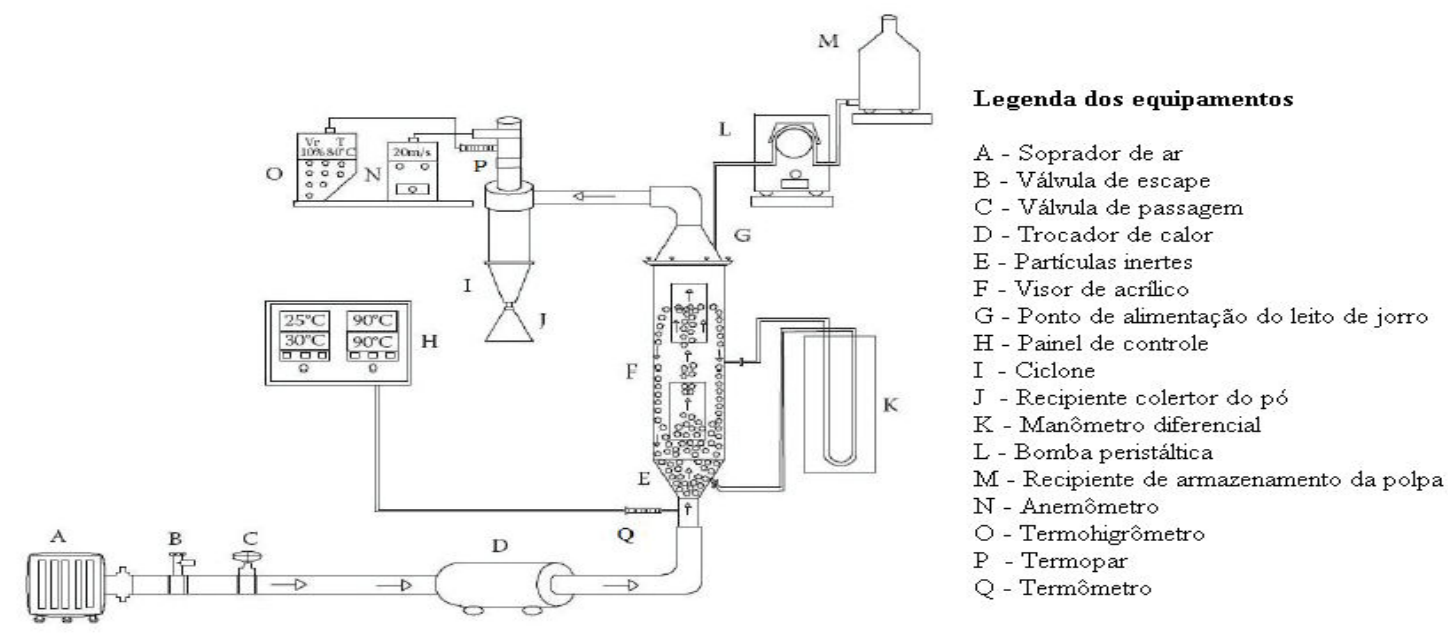

\subsection{Metodologia experimental da secagem em leito de jorro}

Os ensaios foram feitos acompanhando planejamento experimental cúbico composto central rotacionado, sendo dois fatores independentes, a temperatura e vazão de ar, de dois níveis, com três repetições no ponto central e o conjunto de corridas experimentais feito em duplicata. Desta forma, foram feitos, ao todo, 22 experimentos. As variáveis de resposta analisadas foram o rendimento de produção de pó e a taxa de produção.

Para realização de cada ensaio de secagem foram primeiramente colocados, aproximadamente, $3 \mathrm{~kg}$ de partículas de PEAD (polietileno de alta densidade), previamente higienizadas no leito. Em seguida, o sistema de medição e aquisição de dados composto por controlador lógico programável conectado a um laptop foi ligado e então, acionado o soprador sendo feito o ajuste da vazão de ar através da válvula de passagem conforme a especificação para cada experimento. Feito isto, foi ligado o trocador de calor, sendo feito ajuste da temperatura por meio de controlador a este associado.

Após isto, aguardou-se um tempo de aproximadamente 30 minutos para estabilização da temperatura no sistema se secagem e só então uma amostra previamente preparada de aproximadamente $150 \mathrm{~g}$ de polpa foi alimentada no leito com auxílio de bomba peristáltica. A alimentação foi contínua e a vazão de $10 \mathrm{~g} / \mathrm{min}$. O pó produzido foi coletado em recipiente de vidro acoplado ao ciclone. O mesmo foi mantido acondicionado, livre de contato com o ar, e pesado.

O teor de umidade da polpa foi medido, bem como do pó obtido, através de analisador de umidade eletrônico. Desta maneira foi possível determinar o rendimento mássico de produção do pó a partir da Equação 1. Quanto à taxa média de produção de pó, foi determinada pelo quociente da massa produzida pelo intervalo de tempo do início do experimento à estabilização da umidade do ar.

$$
\eta_{p o}=\frac{m_{p \dot{o}}\left[\left(1-X_{p o}\right) \square 00\right.}{m_{p o l p a} \square\left(1-X_{p o l p a}\right)}
$$




\section{RESULTADOS E DISCUSSÃO}

A matriz experimental para um delineamento cúbico composto central rotacionado, com três repetições no ponto central, contendo as respostas para rendimento e taxa de produção de pó é apresentada na Tabela 1. A umidade da polpa foi medida antes dos experimentos e teve como resultado $93,41 \%$ b.u.

Tabela 1- Respostas da avaliação do processo quanto ao rendimento, taxa de produção de pó e umidade.

\begin{tabular}{ccccccc}
\hline Corrida & Replicata & $\begin{array}{c}\text { Temperatura } \\
\left({ }^{\circ} \mathrm{C}\right)\end{array}$ & $\begin{array}{c}\text { Vazão de ar } \\
(\text { xQjm })\end{array}$ & $\begin{array}{l}\eta \text { pó}(\%) \\
\text { m'pó } \\
(\mathrm{g} / \mathrm{h})\end{array}$ & Xpó(\% b.u.) \\
\hline 1 & 1 & $-1(60)$ & $-1(1,2)$ & 8,7 & 1,6 & 2,9 \\
2 & 1 & $-1(60)$ & $+1(1,3)$ & 9,52 & 1,2 & 2,9 \\
3 & 1 & $+1(70)$ & $-1(1,2)$ & 10,32 & 2,7 & 2,1 \\
4 & 1 & $+1(70)$ & $+1(1,3)$ & 10,95 & 2,2 & 1,9 \\
5 & 1 & $-1,41(57,9)$ & $0(1,25)$ & 10,27 & 1,7 & 3,4 \\
6 & 1 & $+1,41(72,1)$ & $0(1,25)$ & 12,46 & 4,2 & 1,6 \\
7 & 1 & $0(65)$ & $-1,41(1,18)$ & 8,02 & 1,6 & 2,9 \\
8 & 1 & $0(65)$ & $+1,41(1,32)$ & 13,36 & 5,4 & 12,2 \\
$9(\mathrm{C})$ & 1 & $0(65)$ & $0(1,25)$ & 9,24 & 1,6 & 5,3 \\
$10(\mathrm{C})$ & 1 & $0(65)$ & $0(1,25)$ & 9,61 & 2,5 & 6,1 \\
$11(\mathrm{C})$ & 1 & $0(65)$ & $0(1,25)$ & 13,33 & 2,8 & 6,6 \\
12 & 2 & $-1(60)$ & $-1(1,2)$ & 7,71 & 1,6 & 3,1 \\
13 & 2 & $-1(60)$ & $+1(1,3)$ & 6,76 & 1,1 & 3,1 \\
14 & 2 & $+1(70)$ & $-1(1,2)$ & 10,08 & 2,1 & 2,1 \\
15 & 2 & $+1(70)$ & $+1(1,3)$ & 9,38 & 1,7 & 1,9 \\
16 & 2 & $-1,41(57,9)$ & $0(1,25)$ & 5,89 & 0,9 & 5,9 \\
17 & 2 & $+1,41(72,1)$ & $0(1,25)$ & 17,18 & 4,1 & 1,7 \\
18 & 2 & $0(65)$ & $-1,41(1,18)$ & 10,3 & 2,1 & 2,8 \\
19 & 2 & $0(65)$ & $+1,41(1,32)$ & 8,45 & 1,9 & 8,6 \\
$20(\mathrm{C})$ & 2 & $0(65)$ & $0(1,25)$ & 8,29 & 2,2 & 5,8 \\
$21(\mathrm{C})$ & 2 & $0(65)$ & $0(1,25)$ & 7,8 & 1,4 & 5,9 \\
$22(\mathrm{C})$ & 2 & $0(65)$ & $0(1,25)$ & 7,42 & 1,2 & 5,6 \\
\hline
\end{tabular}

É possível observar que o rendimento de produção de pó de cubiu na secagem em leito de jorro variou de $5,89 \%$ a $17,18 \%$, a taxa de produção do pó na secagem situou-se na faixa de 0,9 $\mathrm{g} / \mathrm{h}$ a $5,4 \mathrm{~g} / \mathrm{h}$ e a umidade do pó formado oscilou entre $1,7 \%$ b.u. e $12,2 \%$ b.u.

Com estes dados, foi possível, a partir do software Statistica 7.0 avaliar a influência das variáveis independentes, temperatura e vazão de ar de secagem sobre as respostas rendimento e taxa média de produção de pó, valendo-se dos gráficos de Pareto apresentados na Figura 2, ao nível de confiança de $95 \%$. 


\section{Congresso Brasileiro de Engenharia Química \\ em Iniciação Científica \\ UFSCar - São Carlos - SP \\ 16 a 19 de Julho de 2017}

Figura 2 - Gráficos de Pareto para Rendimento (a) e Taxa média de produção de pó (b).

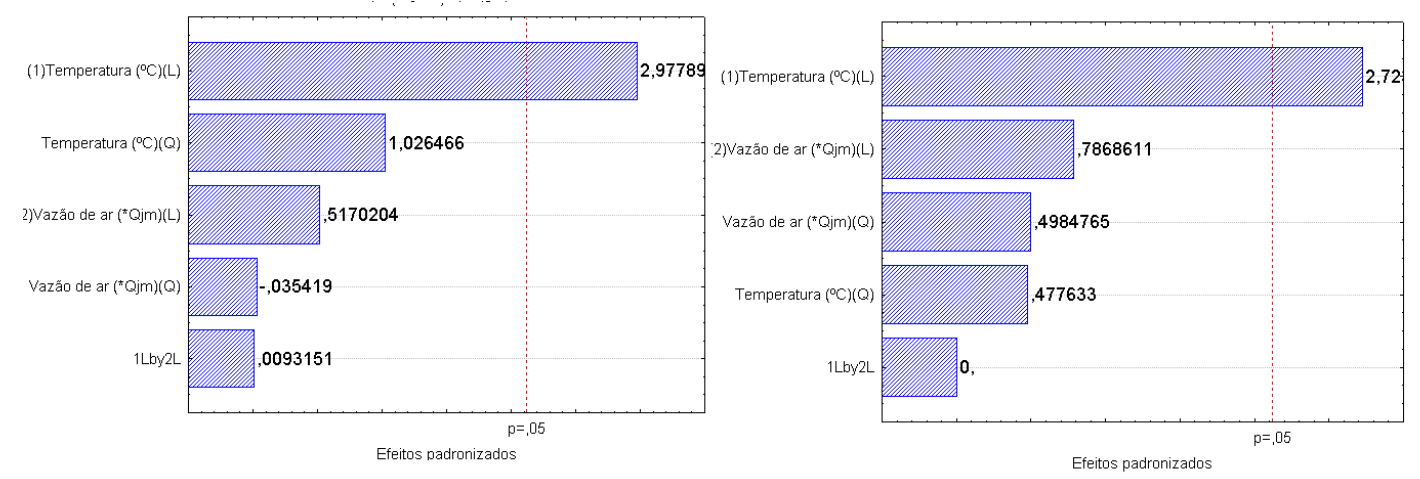

(a) Rendimento

(b) Taxa média de produção de pó

Nota-se, pelos gráficos, que o termo linear da temperatura do ar de secagem é a única variável estatisticamente significante quanto à influência tanto sobre o rendimento como taxa média de produção de pó. Isto contraria o resultado esperado, uma vez que também a variável vazão do ar, em outros estudos de secagem de polpa em leito de jorro mostra-se influente sobre estas respostas (COSTA et. al., 2013). Tanto este resultado, como os valores relativamente limitados de rendimento podem ser explicados pela composição do cubiu, rico em polissacarídeos e com baixo teor de lipídios, ambos fatores que aumentam a retenção de sólidos no leito além de, ao longo dos ensaios, ter sido observada progressiva aderência do pó formado às partículas de PEAD e às paredes do leito (MEDEIROS et. al., 2004).

Foi possível ainda, a partir de estimativa dos coeficientes feita no software, ajustar um modelo estatístico de regressão, dados os resultados obtidos para o rendimento, conforme a Equação 2. Quanto à taxa média de produção de pó, nenhum dos coeficientes de regressão foi estatisticamente significante. Por sua vez a análise de variância, apresentada na Tabela 2 para o rendimento, permite observar a significância do modelo de regressão ajustado.

$$
\eta_{p o}=9,288+3,384 * T
$$

Tabela 2 - Análise de regressão para variável de resposta rendimento

\begin{tabular}{ccccc}
\hline Variável & $\begin{array}{c}\text { Coeficiente } \\
\text { de correlação }\end{array}$ & $\begin{array}{c}\text { Fcalc } \\
\text { Regressão }\end{array}$ & Ftab & $\begin{array}{c}\text { (Fcalc/Ftab) } \\
\text { Regressão }\end{array}$ \\
\hline$\eta_{\text {pó }}$ & 0,626 & 2,062 & 0,124 & 16,642 \\
\hline
\end{tabular}

Conforme os dados apresentados na Tabela 2 sugerem, o modelo ajustado apresentou um coeficiente de correlação relativamente bom, indicando que o ajuste é satisfatório entre os valores observados e preditos nas correlações. Também o teste F indica que o modelo de regressão é estatisticamente significante.

\section{CONCLUSÃO}

Os estudos desenvolvidos permitiram observar que a temperatura é variável de maior influência na produção do pó de cubiu na secagem em leito de jorro, tanto sobre o rendimento como a taxa média de produção do pó. Foi possível, ainda, estabelecer um modelo de regressão 


\section{Congresso Brasileiro de Engenharia Química \\ em Iniciação Científica \\ UFSCar - São Carlos - SP \\ 16 a 19 de Julho de 2017}

que correlaciona satisfatoriamente o rendimento à temperatura do ar de secagem. Além disto, foi notada a viabilidade do processo de secagem da polpa de cubiu em leito de jorro com partículas inertes de PEAD, tendo sido obtido rendimento razoável para baixas temperaturas de ar de secagem, considerando que não houve qualquer adição de agentes espessantes à polpa, como maltodextrina.

\section{NOMENCLATURA}

npó $\quad$ Rendimento de produção de pó (\%)

mpó Massa de pó (g)

m'pó Taxa média de produção de pó $(\mathrm{g} / \mathrm{h})$

mpolpa Massa de polpa (g)

Xpó Teor de umidade do pó (\%b.u.)

Xpolpa Teor de umidade da polpa (\%b.u.)
Qjm Vazão mínima de jorro

$\mathrm{T}$ Temperatura do ar de secagem

$\left({ }^{\circ} \mathrm{C}\right)$

Fcalc Valor calculado de $\mathrm{F}$

Ftab Valor tabelado de F

\section{REFERENCIAS}

CÁNOVAS, G. V. B.; MERCADO, H. V. Dehydration of Foods. Chapman \& Hall: New York, EUA, p. 2-3, 1996.

COSTA, R.G., ANDEROLA K., SILVA, C.A.M., FARIA L.J.G., TARANTO O.P. Estudo da secagem de açaí (Euterpe oleracea Mart) em leito de jorro. Anais do XXXVI Congresso Brasileiro de Sistema Particulados; 20-23 de outubro de 2013; Maceió - AL. Maceió: Editora da UFAL, 2013.

FELLOWS, P. J. Tecnologia do processamento de alimentos: Princípios e prática. 2a edição. Porto Alegre: Artmed, 602p., 2006.

MEDEIROS, Maria de F.D. et al. Drying of pastes in spouted beds: influence of the paste composition on the material. In.: Simpósio Internacional de Secagem, 14, 2004, São Paulo. Anais do $14^{\text {ao }}$ Simpósio Internacional de Secagem. São Paulo, 2004.

MERCADANTE, A. Z. Bioacessibilidade in vitro de compostos fenólicos em frutas: efeito da digestão gastrintestinal na composição e na capacidade desativadora de espécies reativas de oxigênio e de nitrogênio. Faculdade de Engenharia de Alimentos (FEA), Universidade Estadual de Campinas (UNICAMP). 2013.

SILVA FILHO, D. F.; YUYAMA, L. K. O.; AGUIAR, J. P. L; OLIVEIRA, M. C.; MARTINS, L. H. P. Caracterização e Avaliação do Potencial Agronômico e Nutricional de Etnovariedades de Cubiu (Solanum sessiliflorum, Dunal) da Amazônia. Acta Amazonica, v.35, n. 4, p. 399-406, 2005.

SOUZA, J. S. Secagem de Mistura de Polpa de Frutas Tropicais em Leito de Jorro. 2009, 155f. Tese (Doutorado em Engenharia Química). Programa de Pós Graduação em Engenharia Química, Universidade Federal do Rio Grande do Norte, Natal/RN. 